\title{
AN UNUSUAL PRESENTATION OF PELVIC TUBERCULOSIS;
}

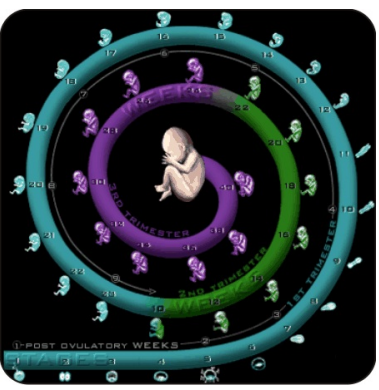

\author{
DR. RAHILA FARHAT CHAUDHRY \\ MBBS, MCPS, FCPS \\ Gynaecologist Social Security Hospital, \\ Faisalabad.
}

\author{
PROF. DR. MAHNAAZ ROOHI \\ MBBS, MRCOG, FRCOG \\ Professor \& Head of Gynae Unit I, \\ Allied Hospital Faisalabad.
}

\begin{abstract}
Tuberculosis is highly prevalent in developing countries like Pakistan and should be considered in the differential diagnosis of patients with pelvic mass, ascites and raised serum CA 125 levels. A case of pelvic tuberculosis with markedly raised serum CA 125 levels and initial diagnosis of ovarian tumour was made.
\end{abstract}

Key words: Pelvic Tuberculosis CA 125, Ovarian Tumour.

\section{INTRODUCTION}

Tuberculosis is a preventable disease that may present in variable ways. In $40 \%$ of the cases of genital tuberculosis, tubercular peritonitis is usually seen and in these cases CA 125 raised $^{1}$. In countries where tuberculosis is present, pelvic tuberculosis should be considered in the diagnosis of pelvic mass with or without ascites. The incidence of tuberculosis in pakistan is 181 per 100,000 individuals and ranked $5^{\text {th }}$ in the world².

A case report is presented.

\section{CASE REPORT}

A 46 years old women, para 3 with last baby, about 7 years of age presented to gynae O.P.D of social security hospital with history of irregular vaginal bleeding for the last 5-6 months. She gave no other significant history.
On physical examination she was an emaciated lady. On vaginal examination uterus was retroverted enlarged with a mass felt in the adnexa. On USG examination thick localized fluid with debris seen in the cul-d-sac surrounding the uterus giving the impression of pyometra. All the routine investigations were done. Her $\mathrm{Hb}$ was $10.5 \mathrm{gm} / \mathrm{dl}$ and her ESR was 65. Her CA was 125 was $325 \mathrm{u} / \mathrm{ml}$. All other tests were normal. A diagnosis of ovarian tumour was made and she was prepared for laparotomy. At laparotomy peritoneal cavity was matted together. Uterus and ovaries could not be identified because they were buried in dense adhesions. Multiple Biopsies were taken from the omentum and the peritoneum. Histopathology report revealed soft tissue tuberculosis and patient was put on anti-tuberculosis therapy including rifampicin, isoniazid, pyrazinamide and inj streptomycin, and she was asked to come for regular follow up after one month. The patient returned one 
month with significant improvement in her general condition.

\section{DISCUSSION}

This case high lights the unusual presentation of tuberculosis. Raised level of CA 125 led to the suspicion of ovarian malignancy. In a retrospective analysis of clinical features of 20 cases of pelvic tuberculosis carries out at Chinese Academy concluded that differentiation of female pelvic tuberculosis from ovarian malignancy is difficult and tuberculosis must be considered in the differential diagnosis especially in developing countries ${ }^{3}$.

Ultrasound has proved to be confusing in cases of pelvic tuberculosis, showing ascites and pelvic mass suggestive of ovarian malignancy ${ }^{4,5}$.

CA 125 is a soluble glycoprotein which is raised in $80 \%$ of patients with ovarian malignancy. And only in $1 \%$ of control $^{6}$. However it is non specific tumour maker as it is elevated in other non malignant conditions like endometriosis. There are some reports linking raised level of CA125 with pelvic tuberculosis ${ }^{5}$ in most cases the levels are $<500 \mathrm{u} / \mathrm{ml}$ and in one series it was 316.6 $\mathrm{u} / \mathrm{ml}^{7}$.

Recently Mas et $\mathrm{al}^{8}$ from Turkey concluded that CA125 levels in patients with pelvic tuberculosis is as high as in ovarian tumors. Simsek et al have reported that level normalizes with the response to anti-tuberculosis therapy ${ }^{7}$.

\section{COMMENTS}

This case report shows that very high levels of CA125 can occur in pelvic tuberculosis and this needs to be in the differential diagnosis as tuberculosis is a curable disease provided the diagnosis is made early and treatment is started.

\section{REFERENCES}

1. Jedberg H. A study on genital tuberculosisin women. Acta Obstet Gynaecol scand 1950; 30 (Suppl 1); 7-176.

2. Avan BI, Fatmi Z, Rashid S. Comparison of clinical and laparoscopic features of infertile women suffering from genital tuberculosis or pelvic inflammatory disease. J Pak Med Assoc 2001; 51; 393-9.

3. Zhi Zj. Analysis of 20 cases of pelvic tuberculosis initially suspected of ovarian tumour 2003 26: 462-4.

4. Nistal de Paz F, Herrero Femendez B, Peez Simon R, Fermendez Perez $E$, et al pelvic peritoneal tuberculosis simulating ovarian carcinoma 1996; 91: 1660-1.

5. Irvin Wp. Rice LW, Andersen WA. Abdominal tuberculosis mimicking metastatic ovarian carcinoma. Obstet Gynaecol 1998; 92: 709.

6. Bast RC Jr, Knapp Rc, The imaging role of monoclonal antibodies in the clinical management of epithelial ovarian carcinoma. In De Vita Jr, Hellman S, Rosenberg SA, important advances in oncology. Philadelphia; lippincot 197; 39.

7. Simsek H, Savas MG, Kadayiefi A, Tatar G. Elevated serum $\mathrm{Ca} 125$ concentration in patients with tuberculous peritonitis; a case control study. Am j Gasstroenterol 1997; 92: 1174-6.

8. Mas MR, Comert B, Saglamkaya U, Yamanei L, Kuzhan $O$ et al CA125; a new marker for diagnosis and follow up of patients with tuberculous paritonitis Dig liver dis 2000; 32: 595-7. 